\title{
Abscess in Primary Tuberculosis of Breast: Case Report
}

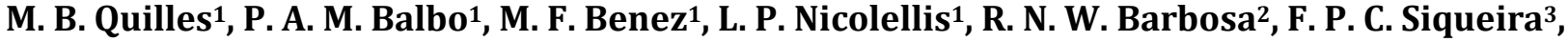 \\ l. T. M. Zutin ${ }^{*}$
}

${ }^{1}$ Medical Academic Marília University-UNIMAR, Marilia, Brazil

${ }^{2}$ Infectivity Department, Marília University, Marilia, Brazil

${ }^{3}$ Woman Health Department, Marília Medical College_FAMEMA, Marilia, Brazil

${ }^{4}$ Collective Health Department, Marília University_UNIMAR, Marilia, Brazil

Email: *lais_zutin@hotmail.com

How to cite this paper: Quilles, M.B., Balbo, P.A.M., Benez, M.F., Nicolellis, L.P., Barbosa, R.N.W., Siqueira, F.P.C. and Zutin, l.T.M. (2017) Abscess in Primary Tuberculosis of Breast: Case Report. Journal of Tuberculosis Research, 5, 161-167. https://doi.org/10.4236/jtr.2017.53018

Received: June 30, 2017

Accepted: August 8, 2017

Published: August 11, 2017

Copyright $\odot 2017$ by authors and Scientific Research Publishing Inc. This work is licensed under the Creative Commons Attribution International License (CC BY 4.0).

http://creativecommons.org/licenses/by/4.0/

\begin{abstract}
Purpose: To highlight the diagnostic challenges of breast tuberculosis. Mammary tuberculosis is a rare disease. Its clinical and radiological characteristics are similar to other breast diseases in young women, such as granulomatous mastitis and breast carcinoma. Materials and Methods: We report a case of primary tuberculosis of a 34 years old woman who presented bilateral abscess with refractory secretion of blood and pus drainage to previous treatment with conventional antibiotic therapy of granulomatous mastitis. Results: A tuberculous mammary was observed and confirmed in the case. The diagnosis was based on imaging tests and complementary tests. Anti-tuberculosis treatment was prescribed during 6 months, and the evolution was favorable for one patient. Conclusion: Tuberculosis continued to present diagnostic difficulties, particularly in its breast tuberculosis form.
\end{abstract}

\section{Keywords}

Breast, Infections, Tuberculosis

\section{Introduction}

Infection with Mycobacterium tuberculosis (M. tuberculosis) is a clinical disease in developing countries, and is declining in developed nations. However, in the 1980s and 1990s, we have had a return to the prevalence of the disease by the HIV/AIDS epidemic associated with its multidrug resistance. Extrapulmonary manifestations occur in few cases. Mammary tuberculosis is a rare condition that is important because of differential diagnosis with other pathologies of this 
organ [1].

It presents an incidence less than $0.1 \%$ of the mammary lesions analyzed histologically [2] [3]. The nodular form may mimic a carcinogen or pyogenic abscess [4] [5]. The presence of granulomatous reaction may have several histological hypotheses, such as: aspergillosis and schistosomiasis [4].

In 1899, Warthin valued the relationship between tuberculous mastitis and breast cancer [6] [7] [8]. In nodular form it may mimic a carcinoma and in the disseminated form, it suggests an inflammatory carcinoma. Abboud et al., 1997 published one of the first cases of the diffuse inflammatory form of the mammary tuberculosis, and the differential diagnosis was initially made with carcinoma, and later confirmed by the culture with the identification of $M$. tuberculosis. The disease affects almost exclusively the female sex, being more common the black woman than the white woman, it is still demonstrated, more often women in the menacme, being the pregnancy and the lactation the periods of greater risk of infection [9]. The main factors of risk include multiparity, lactation, trauma, previous mastitis and AIDS [10] [11].

The diagnosis of extrapulmonary tuberculosis is made by clinical evidence, laboratory findings suggestive of active forms in patients with at least one culture positive for M. tuberculosis of extrapulmonary material [3].

Considering the scarcity of described cases in the literate, we report a case of primary tuberculosis of a 34 years old woman who presented bilateral abscess with refractory secretion of blood and pus drainage to previous treatment with conventional antibiotic therapy of granulomatous mastitis.

\section{Methodology}

It is a cross-sectional, retrospective and descriptive study, based on the casestudy of breast tuberculosis. The data were obtained from the patient's chart accompanied by the Department of Health and Hygiene (DHS) of the city of Pompéia (SP) in the year 2016. A review of the main publications on breastfeeding tuberculosis in the literature was done by consulting the databases COCHRANE (http://www.cochrane.org/) and MEDLINE/PubMed

(http://www.ncbi.nlm.nih.gov/pubmed). The work was submitted and approved by the Unimar Ethics Committee, under the approval number \#1758270.

\section{Case Report}

D.M.N.S, 34 years old, female, married, black, native of Pompéia-SP, seller. G1P1A0, exclusive breastfeeding up to 6 months, denies a history of breast cancer among relatives and with these socioeconomic characteristics (Table 1): (1)

Table 1. Socioeconomic characteristics.

\begin{tabular}{ccccc}
\hline House & Convenients & People in house & Per capita income & Schooling \\
\hline Masonry & 6 & 4 & 150,00 & Compulsory only \\
\hline
\end{tabular}


The patient lives in Pompeia-SP and there were 2 cases of pulmonary tuberculosis in 2013 in people above 15 years old and 1 case below this age. In this time was analyzed an average around three times less in Pompeia than national average (Graphic 1): (1).

She attended the DHS, therefore letter of referral from the Infectology sector, with the purpose to investigate Mammary Tuberculosis. It refers to one year of follow-up with an astrologist, due to a history of nodular lesions in the high lateral quadrant (HLQ), right breast associated with edema, erythema, local heat and pain, with evolution to spontaneous abscess and fistulization. Mammographic examination identified lesions of irregular borders and heterogeneous content in HLQ of the right breast, with dimensions of $2.0 \times 1.9 \times 1.7 \mathrm{~cm}$. Lymph nodes with a slightly enlarged larynx, measuring $1.6 \times 1.0 \mathrm{~cm}$, were also observed. Magnetic resonance imaging showed extensive non-nodular enhancement with regional distribution in the upper quadrants of the right breast, with homogeneous internal enhancement, measuring about Of $7.5 \times 7.1 \times 7.5$ $\mathrm{cm}$, signs of skin edema surrounding the non-nodular enhancement described, axillary lymph node enlargement, measuring $1.7 \mathrm{~cm}$. BI-RADS ${ }^{\bullet}: 5$. The histopathological examination of the material obtained by CORE-BIÓPSIA guided by ultrasonography evidenced exuberant granulomatous mastitis.

Complementary tests such as blood count, blood glucose, sodium, potassium, creatinine and CRP showed no alterations. He underwent several drug treatments (Predinisone, Ciprofloxacin, Bactrin) without improvement of the condition.

Patient, five months after biopsy, returns with similar complaint in the left breast. On examination of the right breasts, HLQ operative scar, right nipple retraction, abscessed lesion, and palpable nodule in the medium segment of the left breast (MSLB) of hardened consistency, with positive expression of serosanguineous staining (Figure 1 and Figure 2) were noted. Ultrasound examination shows a circumscribed content composed of a solid/cystic component of approximately $2.0 \times 0.5 \mathrm{~cm}$ in MSLB of indeterminate nature with reaction lymph node measuring $1.6 \times 1.0 \mathrm{~cm}$. In nuclear magnetic resonance, the presence of homogeneous internal enhancement, measuring about $9.0 \times 6.4 \mathrm{~cm}$, followed by organized net collection in the anterior and medial third of the left

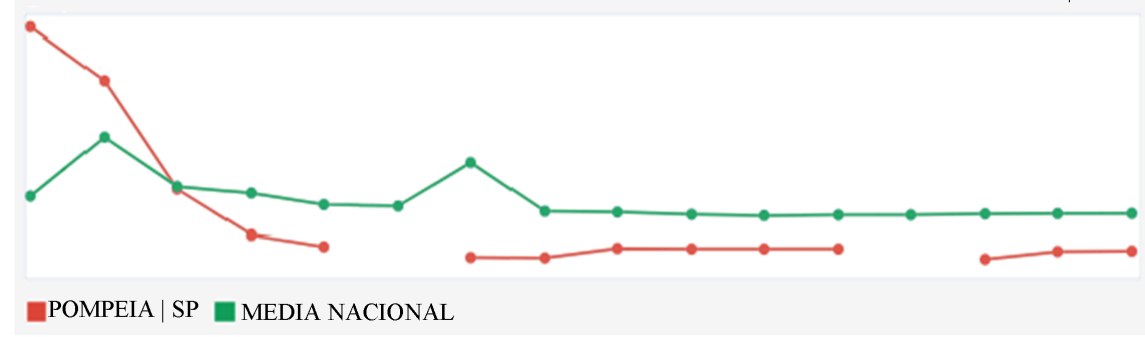

Graphic 1. Number of cases in the population. 


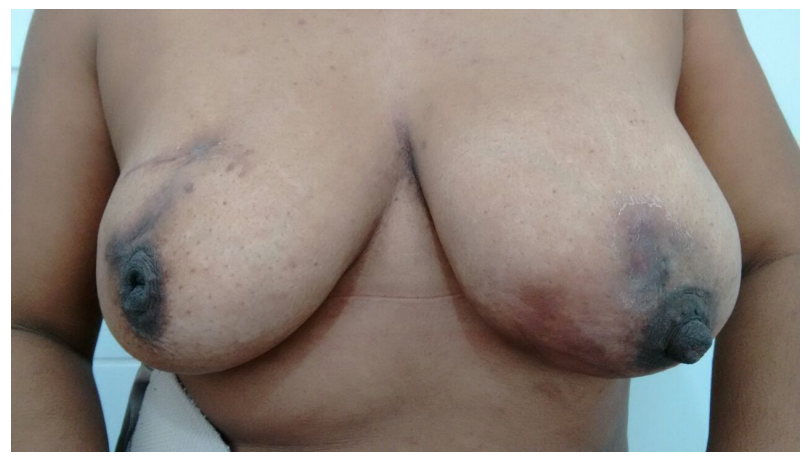

Figure 1. Mammary lesion.

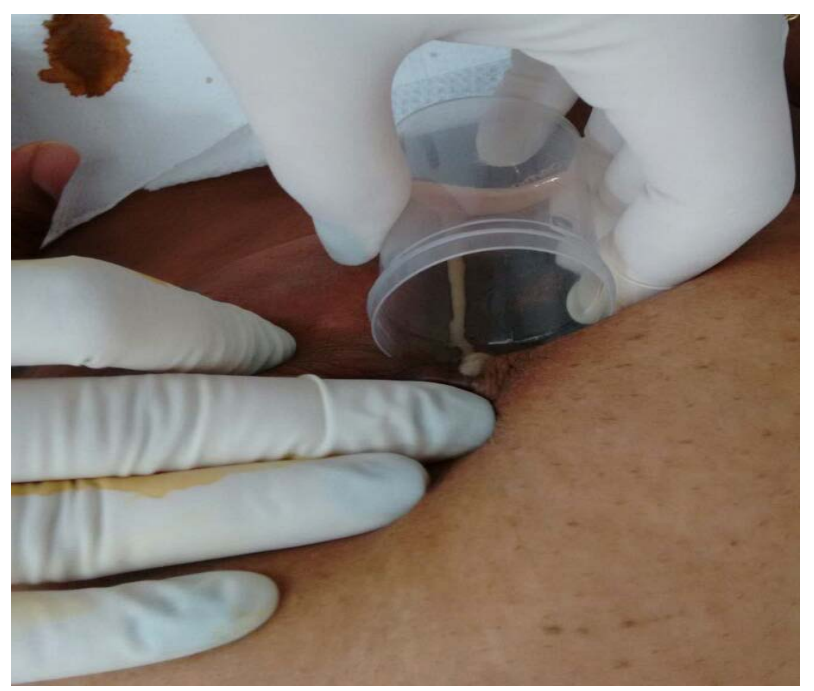

Figure 2. Drainage of secretion.

peripapillary region, measuring $2.0 \times 1.2 \times 1.2 \mathrm{~cm}$, Another area of similar characteristics is noted in the middle third of the inferolateral quadrant measuring $1.3 \times 0.5 \times 0.9 \mathrm{~cm}$ (Figure 3). Bilateral lymph nodes measuring approximately $2.6 \mathrm{~cm}$. Performed complementary tests such as antinuclear antibody (ANA), chest X-ray, Thyroid stimulant hormone (TSH), thyroglobulin (T4), C-reactive protein (PCR), without alterations. Cutaneous tuberculin test negative and culture for acid alcohol resistance bacillus (AARB) positive.

Due to the suspicion of tuberculous lesion, empiric treatment was started, with a quadruple regimen for tuberculosis Rifampcine $150 \mathrm{mg}$, Isoniazid $75 \mathrm{mg}$, Piracinamide $400 \mathrm{mg}$, Etambutol Hydrochloride $275 \mathrm{mg}$ supervised by the health team, carried out a notification, requested secretion culture for research histochemistry for alcohol-acid-resistant bacilli AABR, cutaneous tuberculin test and sorology for HIV.

Two weeks later was indentified the two samples of AABR as positive, but negative to cutaneous tuberculin test and HIV sorology. Considering the results and the empiric test with good answer was definitive the diagnose of breast tuberculosis without pulmonary tuberculosis (2).

After five months of treatment the patient moved to other house and doesn't 


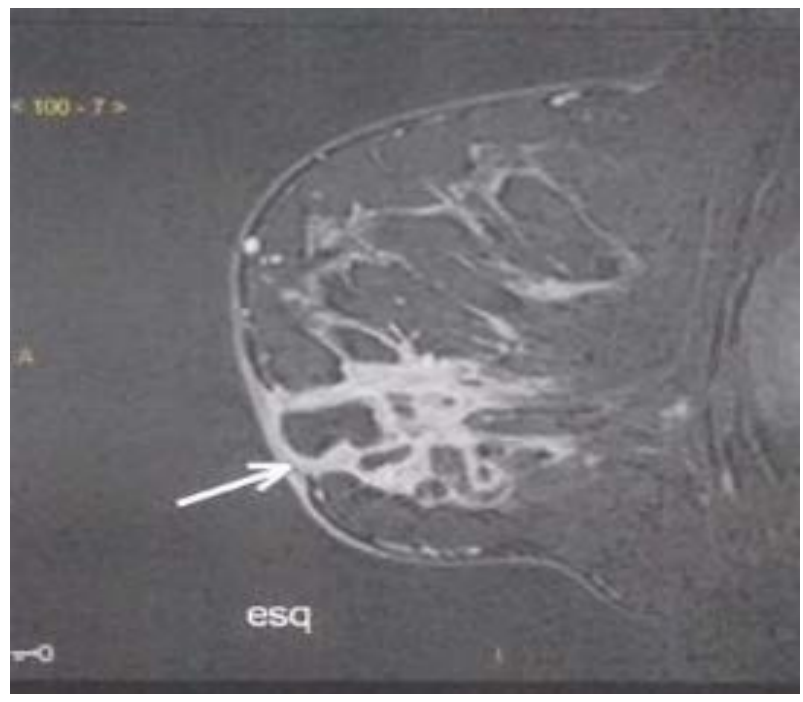

Figure 3. Magnetic resonance of breast $\mathrm{E}$.

to appear to consult, ergo, is not possible to compare pictures after the treatment (3).

\section{Discussion}

Described in the early nineteenth century, breast tuberculosis persists as a rare disease to date, ranging from less than $1 \%$ in developed countries to $3 \%-5 \%$ of breast diseases in underdeveloped countries such as India [12]. It is basically divided into primary and secondary, the first form being defined when no other M. tuberculosis infection site is identified, and is caused by direct inoculation into the mammary tissue [13].

Breast tuberculosis usually occurs in women of reproductive age [14]. Although breast tissue is quite resistant to infection by $M$. tuberculosis, changes occurring during the woman's fertile age predispose more easily to trauma and consequently to infection [15], particularly during pregnancy and breastfeeding [14] [16]. Bilateral involvement is rare (3\%) [16].

The most common nodular form begins as a painless mass that progresses with posterior cutaneous involvement and the formation of ulcers with draining sinuses. The diffuse form is characterized by multiple drainage foci, with an important inflammatory process and axillary involvement. The less common sclerosing form occurs in elderly women and presents a higher degree of fibrosis, with little suppuration or caseation, and it is frequent to have nipple retraction [14].

The gold standard for the definitive diagnosis of breast tuberculosis consists of the identification of its etiologic agent, M. tuberculosis, by direct optical microscopy with Ziehl-Neelsen staining or by culture of the aspirated material. However, the rate of detection of acid-alcohol bacilli resistant to Ziehl-Neelsen staining is low and cultures are negative in most cases. Diagnosis, in most cases, can only be established by histology, by identifying the presence of granulomatous lesions with typical caseous necrosis [17] [18]. 
The curative treatment is usually done empirically with tuberculostatics, usually in six-month regimens, sometimes requiring a surgical approach with drainage or even mastectomy, $10 \%$ of cases requiring simple mastectomy due to lack of response to therapy, but were Large lesions and of prolonged duration [8] [11] [19].

In the clinical case presented, it is a young patient with no personal or family history of tuberculosis or mammary neoplasia, whose presentation of the disease was a bilateral mammary tumor, with phlogistic signs, tissue retraction and secretory abscess. He was evaluated by a range of specialists assisted by imaging, laboratory and histopathological analysis, thus, granulomatous discarding mastitis and breast carcinoma, respectively.

\section{Conclusion}

Therefore, based on previous researches on the description of similar cases, a protocol was opened for breast-borne tuberculosis and concomitant empirical treatment of the patient and the positive test of AARB. Due to the rarity of the pathology mentioned in the present report, it is necessary to investigate differential diagnoses. However, due to the benign evolution of the disease and the failure of the previously performed treatments, the need for mammary tuberculosis research is understood, thus, the patient presented significant clinical improvement after the two weeks of treatment, proving the diagnostic of breast tuberculosis.

\section{References}

[1] Fanlo, P. and Tiberio, G. (2007) Extrapulmonary Tuberculosis. Analesdel Sistema Sanitario de Navarra, 2, 143-162.

[2] Fellah, L., Leconte, I., Weynand, B., Donnez, J. and Berlière, M. (2006) Breast Tuberculosis Imaging. Fertility and Sterility, 86, 460-461. https://doi.org/10.1016/j.fertnstert.2006.03.020

[3] Kervancioglu, S. (2005) Primary Tuberculosis of the Breast. Diagnostic and Interventional Radiology, 11, 210-212.

[4] Jah, A., Mulla, R., Lawrence, F.D., Pittam, M. and Ravichandran, D. (2004) Tuberculosis of the Breast: Experience of a UK Breast Clinic Serving an Ethnically Diverse Population. Annals of the Royal College of Surgeons of England, 86, 416-419. https://doi.org/10.1308/147870804713

[5] Gupta, S., Singh, V.J., Bhatia, G. and Dhuria, K. (2014) Primary Tuberculosis of the Breast Manifested as Abscess: A Rare Case Report. Acta Medica Indonesiana, 46, 51-53.

[6] Barros, A.C.S.D., Silva, H.M.S. and Dias, E.N. (1999) Mastologia: Condutas. Revinter, Rio de Janeiro, 62-65.

[7] Abboud, P., Bancheri, F., Bajolet-Laudinat, O., Beguinot, I., Wahl, P. and Quereux, C. (1997) Tuberculosemammaire. A propos d'uncasàformeinflammatoirediffuse. $J$ Gynecol Obstet Biol Reprod, 26, 822-824.

[8] Lee, C.H. and Sharif, S.Z. (2016) Primary Breast Tuberculosis (TB) in a Patient with Known Invasive Breast Carcinoma: A Case Report. Medical Journal of Malaysia, 71, 149-151. 
[9] Tauro, L.F., Martis, J.S., George, C., Kamath, A., Lobo, G. and Hedge, B.R. (2011) Tuberculous Mastitis Presenting as Breast Abscess. Oman Medical Journal, 26, 5355. https://doi.org/10.5001/omj.2011.14

[10] Wani, I., Lone, A.M., Malik, R., Wani, K.A., Wani, R.A., Hussain, I., Thakur, N. and Snabel, V. (2011) Secondary Tuberculosis of Breast: Case Report. ISRN Surgery, 2011, Article ID: 529368. https://doi.org/10.5402/2011/529368

[11] Perrone, C., Altieri, A.M., D’Antonio, S., Leonetti, C. and Alma, M.G. (2006) Breast Tuberculosis after Chest Trauma-A Case Report and Review of the Literature. Epub-Eletronic Publication, 3, 200-203.

[12] Goksoy, E., Duren, M., Durgun, V. and Uygun, N. (1995) Tuberculosis of the Breast. European Journal of Surgery, 161, 471-473.

[13] Mendes, W.S., Levi, M. and Levi, G.C. (1996) Tuberculose mamária: Relato de caso e revisão de literatura. Rev HospClínFac Med São Paulo, 51, 136-137.

[14] Shinde, S.R., Chandawarkar, R.Y. and Deshmukh, S.P. (1995) Tuberculosis of the Breast Masquerading as Carcinoma: A Study of 100 Patients. World Journal of Surgery, 19, 379-381. https://doi.org/10.1007/BF00299163

[15] Mukerjee, P., George, M., Maheshwari, H.B. and Rao, C.P. (1974) Tuberculosis of the Breast. Journal of the Indian Medical Association, 62, 410-412.

[16] Banerjee, S.N., Ananthakrishnan, N., Mehta, R.B. and Prakash, S. (1987) Tuberculous Mastitis: A Continuing Problem. World Journal of Surgery, 11, 105-109. https://doi.org/10.1007/BF01658471

[17] Kakkar, S., Kapila, K., Singh, M.K. and Verma, K. (2000) Tuberculosis of the Breast. A Cytomorphologic Study. Acta Cytologica, 44, 292-296. https://doi.org/10.1159/000328467

[18] Hofman, V., Selva, E., Landraud, L., Sicard, D., Vénissac, N., Castillo, L., Kermarec, A., Mouroux, J., Dellamonica, P. and Hofman, P. (2003) Value of PCR Amplification from Formalin-Fixed-Embedded Tissues in the Diagnosis of Mycobacterium tuberculosis Infection. Annales de Pathologie, 23, 206-215.

[19] Shinde, S.R., Chandawarkar, R.Y. and Deshmukh, S.P. (1995) Tuberculosis of the Breast Masquerading as Carcinoma: A Study of 100 Patients. World Journal of Surgery, 19, 379-381. https://doi.org/10.1007/BF00299163

\section{Submit or recommend next manuscript to SCIRP and we will provide best service for you:}

Accepting pre-submission inquiries through Email, Facebook, LinkedIn, Twitter, etc. A wide selection of journals (inclusive of 9 subjects, more than 200 journals)

Providing 24-hour high-quality service

User-friendly online submission system

Fair and swift peer-review system

Efficient typesetting and proofreading procedure

Display of the result of downloads and visits, as well as the number of cited articles

Maximum dissemination of your research work

Submit your manuscript at: http://papersubmission.scirp.org/

Or contact jtr@scirp.org 